\title{
Ketamine used as an acesodyne in human breast cancer therapy causes an undesirable side effect, upregulating anti-apoptosis protein Bcl-2 expression
}

\author{
H. He ${ }^{1}$, J. Chen ${ }^{1}$, W.P. Xie ${ }^{2}$, S. Cao ${ }^{1}$, H.Y. Hu ${ }^{1}$, L.Q. Yang ${ }^{3}$ and B. Gong ${ }^{1}$ \\ ${ }^{1}$ Department of Anesthesiology, \\ Shanghai Changning Maternity and Infant Health Hospital, Shanghai, China \\ 2Department of Anesthesiology, Chinese People's Armed Police Forces, \\ Shanghai Municipal Hospital, Shanghai, China \\ ${ }^{3}$ Department of Anesthesia, Second Affiliated Hospital of Nanchang University, \\ Nanchang, China \\ Corresponding author: B. Gong \\ E-mail: 13661908202@163.com
}

Genet. Mol. Res. 12 (2): 1907-1915 (2013)

Received February 9, 2012

Accepted August 6, 2012

Published January 4, 2013

DOI http://dx.doi.org/10.4238/2013.January.4.7

\begin{abstract}
Ketamine is a dissociative anesthetic agent that has been widely used in surgery and for relieving pain in chronic cancer patients. We applied ketamine to breast cancer cell line MDA-MB-231 to detect the effect of treatment and molecular mechanisms involved. We found that ketamine can upregulate the level of anti-apoptosis protein Bcl-2, which promotes breast cancer cell invasion and proliferation. Knockdown of Bcl-2 could inhibit the increase of Bcl-2 and reduce the invasion and proliferation caused by ketamine in human breast cancer cells. Our findings provide new insight into the effects of ketamine in cancer treatment; we suggest that ketamine, which has been widely used in cancer operations and for relieving pain in chronic cancer patients, may be not the best choice because it can worsen the cancer through promotion of anti-apoptosis.
\end{abstract}

Key words: Ketamine; Bcl-2; Breast cancer 


\section{INTRODUCTION}

Breast cancer is one of the main causes of female cancer death and the most common form of cancer in the world. Invasive growth, metastatic capability, and rapid proliferation are the key reasons for breast cancer being so refractory and stubborn (Adams and Cory, 1998). Curing breast cancer requires the clarification of the mechanisms of breast tumor invasion, metastasis, and proliferation and establishment of appropriate blocking channels based on the previous research. The B-cell lymphoma $2(\mathrm{Bcl}-2)$ protein is a conserved member of the Bcl-2 family and plays an important role in regulating apoptosis (Borner, 2003). Bcl-2 activity is associated with $\gamma$-radiation-induced cell death (Sentman et al., 1991). Bcl-2 may also function in an antioxidant pathway that inhibits lipid peroxidation (Hockenbery et al., 1993). An association between the ras gene and Bcl-2 has been reported, suggesting a possible role of the ras gene family in regulating cell death (Haldar et al., 1989; Fernandez-Sarabia and Bischoff, 1993). Members of the Bcl-2 family are critical death regulators that reside immediately upstream of the mitochondria (Adams and Cory, 1998). Bcl-2 is closely related to tumor generation. High Bcl-2 levels are correlated with a worse survival rate in leukemia (Robertson et al., 1996). In high-grade gliomas, the Bcl2 gene family shows upregulated expression in tumors exhibiting recurrence and progression (Krajewski et al., 1997; Strik et al., 1999). The anti-apoptotic effect of Bcl-2 may shift tumors to anaplastic phenotype-necrosis, a cardinal feature of high-grade gliomas (Stegh et al., 2008).

Ketamine is a dissociative anesthetic agent that has been widely used in a variety of surgical procedures. The utility of ketamine as an anesthetic has been hampered by its troublesome psychomimetic effects. Previous studies have shown that analgesia can be produced with subhypnotic doses of intravenous ketamine with a lower frequency of psychomimetic reactions to provide relief for patients experiencing intractable cancer pain (Backonja et al., 1994; Felsby et al., 1996; Ilkjaer et al., 1996; Warncke et al., 1997; Bell et al., 2003; Slatkin and Rhiner, 2003).

As an anesthetic agent or anodyne, ketamine and its side effects have been studied thoroughly, but insufficient research has been carried out to explore the effect of ketamine on cancer therapy. Our results indicated that ketamine might reduce apoptosis in the breast cancer cell line MDA-MB-231. Ketamine promoted the invasion and proliferation of cancer cells, which mediated the upregulation of Bcl-2 expression that resisted cell-programmed apoptosis. To determine whether the side effect of ketamine is caused by Bcl-2, we performed a rescue experiment. We found that knockdown of Bcl-2 rescued the increase in Bcl-2 caused by ketamine, inhibiting invasion and proliferation in MDA-MB-231. Our study provides a new insight into ketamine side effects in cancer therapy. These results highlight a need to determine whether other anesthetic agents or anodynes have this side effect so that safer pain relievers can be chosen for intractable cancer pain.

\section{MATERIAL AND METHODS}

\section{Cell line and culture}

MDA-MB-231 cells were purchased from the Cell Bank Type Culture Collection of the Chinese Academy of Sciences (Shanghai, China) and cultured in 1640 medium supplemented with $10 \%$ fetal bovine serum (HyClone, Logan, UT, USA), $100 \mathrm{U} / \mathrm{mL}$ penicillin (Gibco BRL, Paisely, Scotland), and $100 \mu \mathrm{g} / \mathrm{mL}$ streptomycin (Gibco BRL), and grown in an incubator at $37^{\circ} \mathrm{C}$ in a humidified atmosphere containing $5 \% \mathrm{CO}_{2}$. 


\section{Transwell assay}

Invasion assays were carried out using a modified transwell chamber system as follows: cells $\left(2 \times 10^{5}\right)$ were seeded on $500 \mathrm{ng} / \mathrm{mL}$ Matrigel-coated (BD Bioscience-Laware, Bedford, MA, USA) membrane inserts with a pore size of $8 \mathrm{~mm}$ (BD Bioscience, San Jose, CA, USA). The same medium was placed in the lower well. The cells were then incubated for $24 \mathrm{~h}$ in the presence of ketamine dissolved in $0.9 \% \mathrm{NaCl}$ or $0.9 \% \mathrm{NaCl}$ without ketamine as a negative control. The cells on the upper side were scraped off. The cells that had migrated into the lower compartment were fixed ( $4 \%$ paraformaldehyde in phosphate-buffered saline), stained with 4',6-diamidino-2-phenylindole, and counted in 5 random high power fields at 200X magnification in each well.

\section{Methyl thiazolyl tetrazolium (MTT) assay}

Cells were cultured on 96-well plates for varying periods of time and exposed to fresh media every other day. The cells were treated with MTT (50 $\mu$ g per well; Sigma, St. Louis, MO, USA). The generated formazan was dissolved with dimethyl sulfoxide and measured at $570 \mathrm{~nm}$ to assess cell viability.

\section{Vector constructs}

The details of the creation of RCAS-Bcl-2 are described elsewhere (Ikegaki et al., 1994).

\section{Western blotting analysis}

Cells were lysed with lysis buffer $(0.5 \mathrm{~mL} 0.5 \mathrm{M}$ Tris-HCl, $\mathrm{pH}$ 6.8, $0.1 \mathrm{~g}$ dithiothreitol, $0.1 \mathrm{~g}$ sodium dodecyl sulfate, $0.005 \mathrm{~g}$ bromophenol blue, and $0.5 \mathrm{~mL}$ glycerine). Equal amounts of protein were loaded on $10 \%$ sodium dodecyl sulfate polyacrylamide gel electrophoresis and then transferred to a nitrocellulose membrane. The membrane was incubated with primary antibodies for $12 \mathrm{~h}$ at $4^{\circ} \mathrm{C}$ against Bcl-2 and $\beta$-actin (Cell Signaling). After the membrane was incubated with appropriate secondary antibodies, signals were visualized with enhanced chemiluminescence.

\section{Transfection assays}

For transfection, cells were grown to $80 \%$ confluency and transfected with Bcl-2 small interfering RNA (siRNA; Santa Cruz, Bcl-2 siRNA (h): sc-29214) using Lipofectamine 2000 (Invitrogen, Carlsbad, CA, USA), according to manufacturer recommendations.

\section{Quantitative real-time polymerase chain reaction (PCR)}

Total RNA isolated using Trizol (Sigma) was subsequently reverse transcribed to complementary DNA using Oligo(dT) 12-18 Primer from $2 \mu \mathrm{g}$ total RNA. The quantitative real-time PCR primer sequences were as follows: Bcl-1 (forward: 5'-CTGCACCTGACGCCC TTCACC-3'; reverse: 5'-CACATGACCCCACCGAACTCAAAGA-3'); $\beta$-actin (forward: 5'-AGCGAGCATCCCCCAAAGTT-3'; reverse: 5'-GGGCACGAAGGCTCATCATT-3'). The 
reactions were placed on a 96-well plate using an Mx3000P system (Stratagene). The amount of target gene expression $\left(2^{-\Delta \Delta \mathrm{Ct}}\right)$ was normalized using the endogenous $\beta$-actin reference.

\section{Statistical analysis}

The results were evaluated using the Student $t$-test for unpaired data. Statistical significance was defined as values of $\mathrm{P}<0.05, \mathrm{P}<0.01$, and $\mathrm{P}<0.001$. Values are reported as means \pm SD.

\section{RESULTS}

\section{Ketamine promotes the invasiveness of MDA-MB-231 cells}

To study the effect of ketamine on the invasion capability of MDA-MB-231 cells, we performed a transwell invasion assay in a dosage experiment. We prepared the ketamine solution using $0.9 \% \mathrm{NaCl}$ solution. MDA-MB-231 cells treated with ketamine $(1,10$, and 100 $\mu \mathrm{M})$ for $24 \mathrm{~h}$ were plated in the upper chamber, and the cells that moved to the underside of the coated membrane were counted. The results showed that the number of cells that invaded the lower chamber was significantly increased approximately 1-fold by the 24-h ketamine treatment. Such a significant increase was treated with the concentration of $100 \mu \mathrm{M}$ ketamine (Figure 1). We found that ketamine may be harmful for breast cancer therapy owing to its promotion of MDA-MB-231 cell invasiveness.

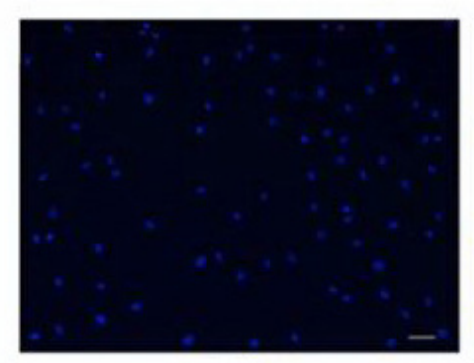

Control

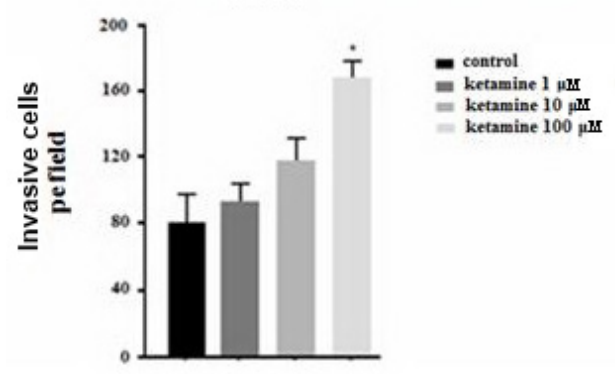

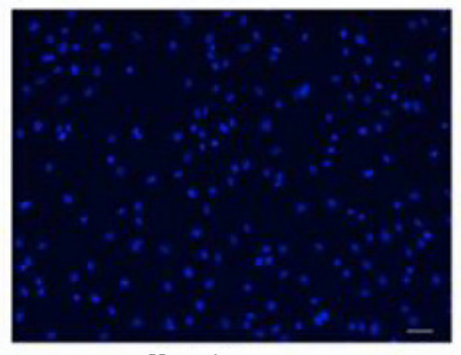

Ketarine

Figure 1. Ketamine promotes the invasiveness of MDA-MB-231 cells. MDA-MB-231 cells were treated with ketamine $(1,10,100 \mu \mathrm{M})$ for $24 \mathrm{~h}$ and detected by transwell invasion assays. Representative photomicrographs of ketamine (100 $\mu \mathrm{M}$, top) showing membrane-associated cells assayed using DAPI staining (200X). Quantitative analysis (bottom) of the invasion $(1,10,100 \mu \mathrm{M})$ in MDA-MB-231 cells. All data are reported as means \pm SD for 3 independent experiments. $* \mathrm{P}<0.05$. Control $=$ cells treated with only $0.9 \% \mathrm{NaCl}$ without ketamine. 


\section{Ketamine can promote the proliferation of MDA-MB-231 cells}

Our MTT assay also detected the effect of ketamine on MDA-MB-231 cell proliferation, and we found that ketamine promoted proliferation (Figure 2). We also studied whether ketamine affected the migration of MDA-MB-231 cells and found that it did not promote migration significantly (data not show). These results indicated that ketamine may enhance the proliferation and invasion of breast cancer cells significantly. According to these results, we concluded that ketamine might be an inappropriate choice to relieve pain because of these side effects.

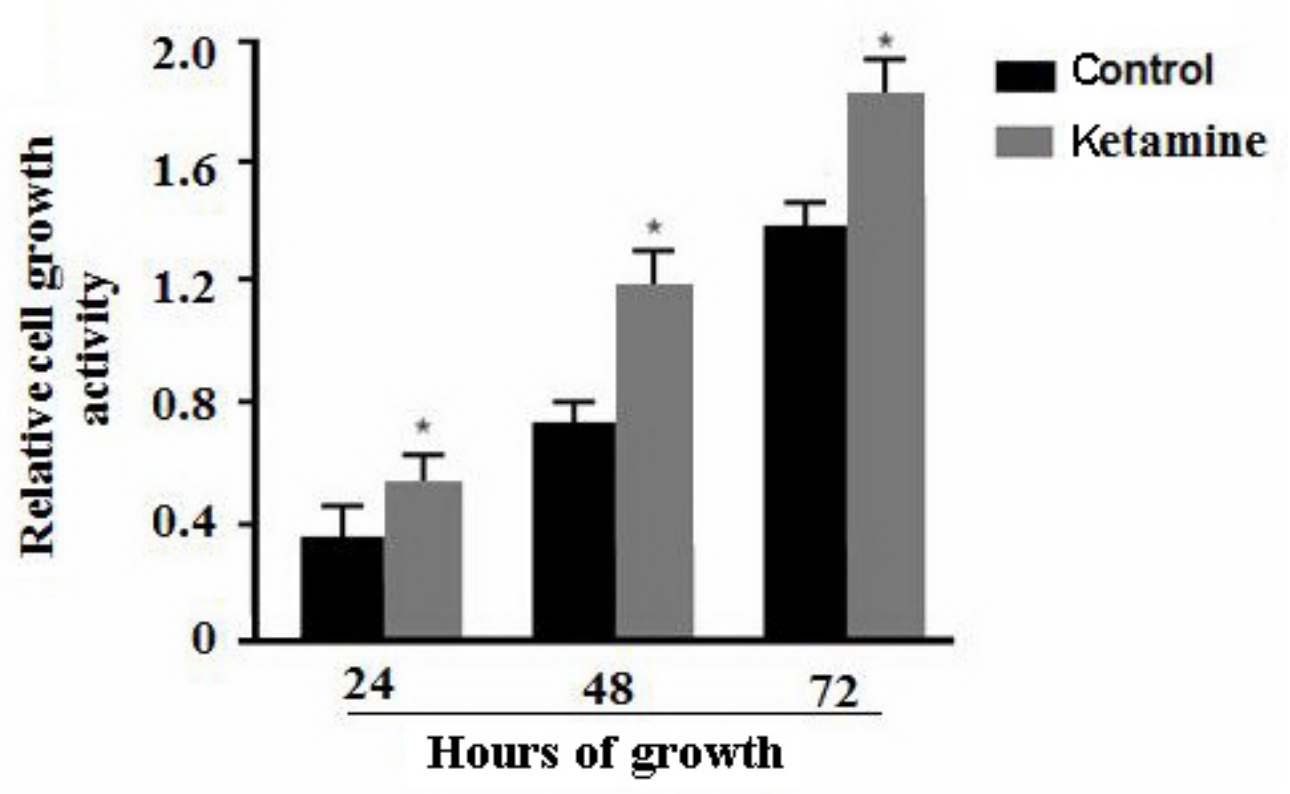

Figure 2. Effect of ketamine on MDA-MB-231 cell proliferation. Cell growth activity of MDA-MB-231 cells at the indicated times as determined by the methyl thiazolyl tetrazolium assay. MDA-MB-231 cells were treated with ketamine $(100 \mu \mathrm{M})$ for $24 \mathrm{~h}$ and detected on $24,48,72 \mathrm{~h}$. Relative cell growth activity is shown. All data are reported as means $\pm \mathrm{SD}$ for 3 independent experiments. ${ }^{*} \mathrm{P}<0.05$. Control $=$ cells treated with $0.9 \% \mathrm{NaCl}$ without ketamine.

\section{Ketamine upregulates expression of Bcl-2 in MDA-MB-231 cells}

We sought the mechanism of this side effect and found that Bcl-2 mRNA and protein levels can be consistently upregulated in MDA-MB-231 cells treated with ketamine compared with effects in negative controls $(0.9 \% \mathrm{NaCl}$ alone; Figure $3 \mathrm{~A})$. Overexpression of Bcl-2 promoted MDA-MB-231 cell invasion (Figure 3B). Bcl-2 also increased the proliferation of cancer cells, which has been demonstrated by previous research (Fanidi et al., 1992) (Figure 3C). 
A

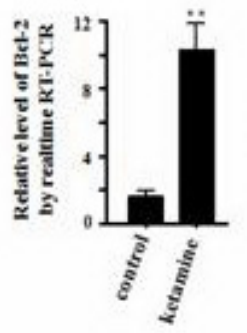

$\mathrm{C}$

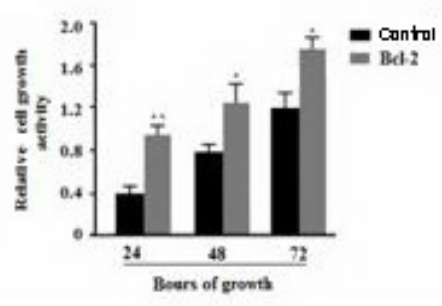

$\mathrm{B}$

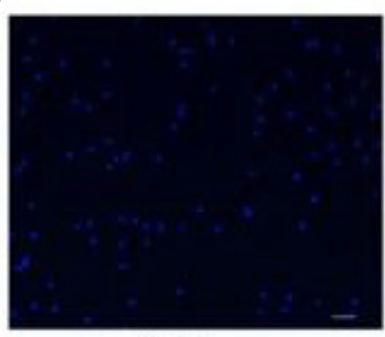

contol

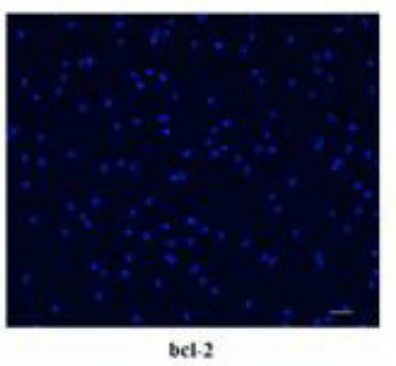

bel-2
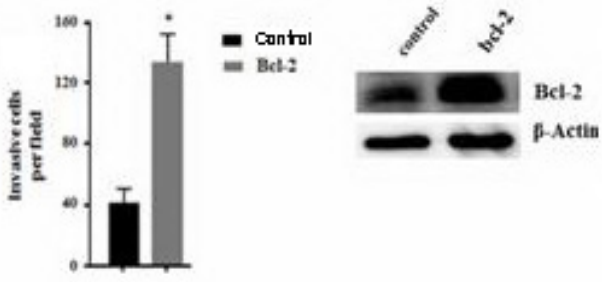

Figure 3. Ketamine upregulates expression of Bcl-2 in MDA-MB-231 cells. A. Analysis of Bcl-2 expression in cells treated with ketamine $(100 \mu \mathrm{M})$ and harvested at $48 \mathrm{~h}$. The protein level of Bcl-2 is upregulated (shown on the right), and the mRNA level is shown on the left. The quantification of 3 independent experiments is shown at the bottom. All data are reported as means $\pm \mathrm{SD}$ for 3 independent experiments. $* * \mathrm{P}<0.01$. Control $=0.9 \% \mathrm{NaCl}$ without ketamine. B. Bcl-2 can promote the invasion of MDA-MB-231 cells. Representative photomicrographs showing membrane-associated cells assayed using DAPI staining (200X, top). Quantitative analysis of the invasion of MDA-MB-231 cells is shown at the bottom. Control = empty vector. C. Detection of the effect of Bcl-2 on proliferation of MDA-MB-231 cells. Relative cell growth activity is shown. All data are reported as means \pm SD for 3 independent experiments. $* \mathrm{P}<0.05, * * \mathrm{P}<0.01$. Control $=$ empty vector.

\section{Ketamine enhances the invasion and proliferation capabilities of MDA-MB-231 cells by upregulating Bcl-2}

To determine whether ketamine enhanced the invasion and proliferation of MDAMB-231 cells by upregulating Bcl-2, we transfected Bcl-2 siRNA into MDA-MB-231 cells treated with ketamine to downregulate the increase of Bcl-2 caused by ketamine. We found that the invasion capability of the cancer cells was similar to that of cells treated with negative siRNA control and $0.9 \% \mathrm{NaCl}$ without ketamine (Figure 4A). We also found that the proliferation of the cancer cells was similar to that of cells treated with negative siRNA control and $0.9 \% \mathrm{NaCl}$ without ketamine (Figure 4B). The rescue experiments showed that ketamine enhanced the invasion and proliferation capabilities of MDA-MB-231 cells by upregulating Bcl-2. 
$\mathbf{A}$

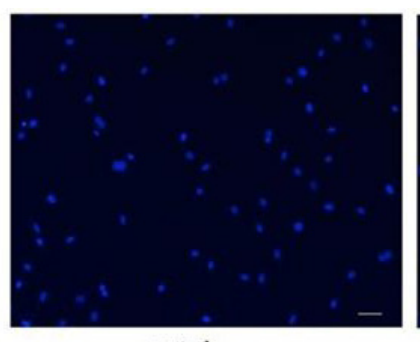

control

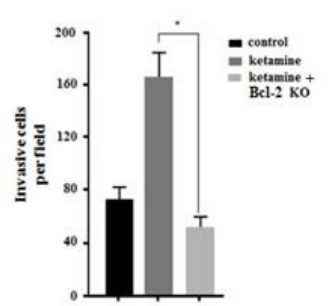

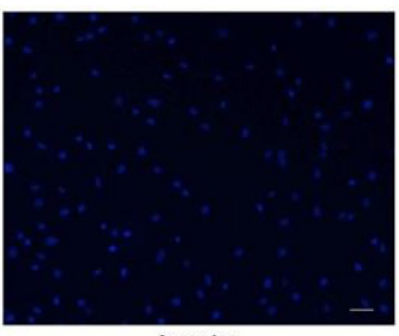

ketamine
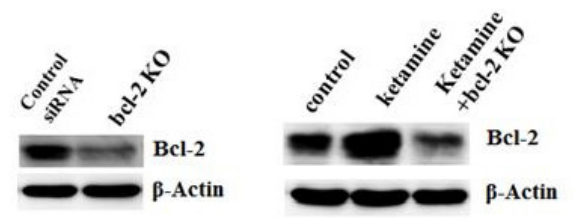

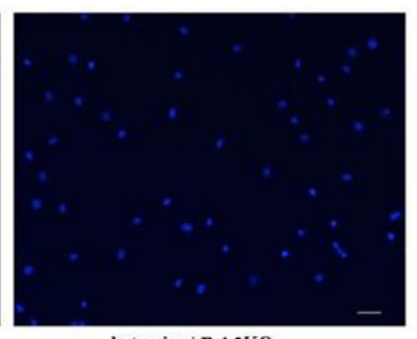

ketamine+Bcl-2KO

B

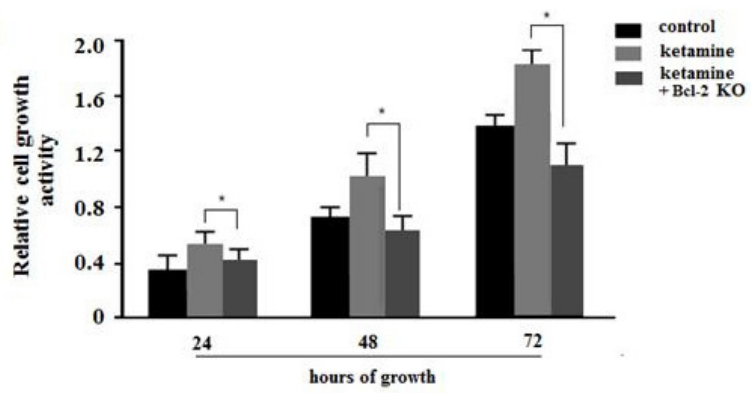

Figure 4. Knockdown of Bcl-2 can reverse the effect of ketamine on invasion and proliferation of MDA-MB-231 cells. A. Representative images are shown on the top, and the quantification is shown at the left bottom. Expression of $\mathrm{Bcl}-2$ on protein level is shown at the right bottom. Bcl-2 $\mathrm{KO}=$ knockdown of Bcl-2 by transfecting Bcl-2 siRNA. Control siRNA means negative siRNA control. All data are reported as means \pm SD for 3 independent experiments. $* \mathrm{P}<0.05,{ }^{*} \mathrm{P}<0.01$. B. Cell proliferation was analyzed by MTT. Control $=$ cells transfected with siRNA negative and treated with $0.9 \% \mathrm{NaCl}$ without ketamine. All data are reported as means $\pm \mathrm{SD}$ for 3 independent experiments. $* \mathrm{P}<0.05$.

\section{DISCUSSION}

Breast cancer incidence is high in women and is the second most frequent cause of mortality in women worldwide. The mechanism of breast cancer generation is complex and remains the subject of debate. It may involve multiple factors. Bcl-2 is regarded as a crucial oncogene that is closely related to tumor generation. Bcl-2 is an anti-apoptosis gene that allows tumor cell escape from programmed apoptosis. Although independent expression of Bcl2 does not result in tumor formation, overexpression of the Bcl-2 gene has been found in a variety of human malignancies (Ikegaki et al., 1994; Monni et al., 1997; Andrews et al., 2004).

Ketamine has been used for more than 30 years to produce anesthesia. For early experience, ketamine can produce analgesia that sometimes well outlasts its anesthetic effects. The mechanisms of the analgesic effects of ketamine are debated (Felsby et al., 1996; Ilkjaer 
et al., 1996; Warncke et al., 1997). Ketamine can be used as a preemptive analgesic (Wong et al., 1997; McCall et al., 2007) for cancer-related pain (Roytblat et al., 1993; Clark and Kalan, 1995; Mercadante et al., 2000) or the diffuse pain of fibromyalgia (Sorensen et al., 1995). Any chemical may have more than one kind of function. Ketamine not only has anesthetic properties but also exerts other effects through action in the cell signaling pathway.

This study revealed that ketamine can promote breast cancer cell line MDA-MB-231 invasion and proliferation by upregulating the expression of Bcl-2. We also found that Bcl2 can affect the invasion capabilities of MDA-MB-231. Knockdown of Bcl-2 reduced the increase of Bcl-2 caused by ketamine and inhibited the invasion and proliferation of MDAMB-231 cells. We concluded that the proliferation may be caused by a reduction in apoptosis induced by ketamine. The invasion capability might occur through several other pathways related to Bcl-2. Therefore, using ketamine to relieve the pain of chronic cancer patients may be harmful, because ketamine can upregulate Bcl-2 expression, reducing apoptosis and promoting the growth of cancer cells. The mechanism through which ketamine affects expression of Bcl-2 is unknown. It may occur through limitation of inhibitors of Bcl-2 or activation of the transcription of Bcl-2. All evidence currently comes from in vitro studies, so the effects in patients must be examined.

Our study provides a new insight into the side effects of ketamine in cancer therapy. We should not only study these side effects in relation to the promotion of cancer growth but also investigate whether other anesthetics have this side effect or can inhibit cancer generation. More studies are also needed to elucidate the mechanism of this effect and discover anesthetic agents and anodynes that are safer than ketamine.

\section{ACKNOWLEDGMENTS}

The authors thank Dr. Guogang Xu for his critical reading of this article.

\section{REFERENCES}

Adams JM and Cory S (1998). The Bcl-2 protein family: arbiters of cell survival. Science 281: 1322-1326.

Andrews GA, Xi S, Pomerantz RG, Lin CJ, et al. (2004). Mutation of p53 in head and neck squamous cell carcinoma correlates with Bcl-2 expression and increased susceptibility to cisplatin-induced apoptosis. Head Neck 26: 870-877.

Backonja M, Arndt G, Gombar KA, Check B, et al. (1994). Response of chronic neuropathic pain syndromes to ketamine: a preliminary study. Pain 56: 51-57.

Bell R, Eccleston C and Kalso E (2003). Ketamine as an adjuvant to opioids for cancer pain. Cochrane Database Syst. Rev. CD003351.

Borner C (2003). The Bcl-2 protein family: sensors and checkpoints for life-or-death decisions. Mol. Immunol. 39: 615647.

Clark JL and Kalan GE (1995). Effective treatment of severe cancer pain of the head using low-dose ketamine in an opioid-tolerant patient. J. Pain Symptom Manage 10: 310-314.

Fanidi A, Harrington EA and Evan GI (1992). Cooperative interaction between c-myc and bcl-2 proto-oncogenes. Nature 359: 554-556.

Felsby S, Nielsen J, Arendt-Nielsen L and Jensen TS (1996). NMDA receptor blockade in chronic neuropathic pain: a comparison of ketamine and magnesium chloride. Pain 64: 283-291.

Fernandez-Sarabia MJ and Bischoff JR (1993). Bcl-2 associates with the ras-related protein R-ras p23. Nature 366: 274275.

Haldar S, Beatty C, Tsujimoto Y and Croce CM (1989). The bcl-2 gene encodes a novel G protein. Nature 342: $195-198$.

Hockenbery DM, Oltvai ZN, Yin XM, Milliman CL, et al. (1993). Bcl-2 functions in an antioxidant pathway to prevent apoptosis. Cell 75: 241-251. 
Ikegaki N, Katsumata M, Minna J and Tsujimoto Y (1994). Expression of bcl-2 in small cell lung carcinoma cells. Cancer Res. 54: 6-8.

Ilkjaer S, Petersen KL, Brennum J, Wernberg M, et al. (1996). Effect of systemic N-methyl-D-aspartate receptor antagonist (ketamine) on primary and secondary hyperalgesia in humans. Br. J. Anaesth. 76: 829-834.

Krajewski S, Krajewska M, Ehrmann J, Sikorska M, et al. (1997). Immunohistochemical analysis of Bcl-2, Bcl-X, Mcl-1, and Bax in tumors of central and peripheral nervous system origin. Am. J. Pathol. 150: 805-814.

McCall TD, Pedone CA and Fults DW (2007). Apoptosis suppression by somatic cell transfer of Bcl-2 promotes Sonic hedgehog-dependent medulloblastoma formation in mice. Cancer Res. 67: 5179-5185.

Mercadante S, Arcuri E, Tirelli W and Casuccio A (2000). Analgesic effect of intravenous ketamine in cancer patients on morphine therapy: a randomized, controlled, double-blind, crossover, double-dose study. J. Pain Symptom Manage 20: $246-252$.

Monni O, Joensuu H, Franssila K, Klefstrom J, et al. (1997). BCL2 overexpression associated with chromosomal amplification in diffuse large B-cell lymphoma. Blood 90: 1168-1174.

Robertson LE, Plunkett W, McConnell K, Keating MJ, et al. (1996). Bcl-2 expression in chronic lymphocytic leukemia and its correlation with the induction of apoptosis and clinical outcome. Leukemia 10: 456-459.

Roytblat L, Korotkoruchko A, Katz J, Glazer M, et al. (1993). Postoperative pain: the effect of low-dose ketamine in addition to general anesthesia. Anesth. Analg. 77: 1161-1165.

Sentman CL, Shutter JR, Hockenbery D, Kanagawa O, et al. (1991). bcl-2 inhibits multiple forms of apoptosis but not negative selection in thymocytes. Cell 67: 879-888.

Slatkin NE and Rhiner M (2003). Ketamine in the treatment of refractory cancer pain: case report, rationale, and methodology. J. Support. Oncol. 1: 287-293.

Sorensen J, Bengtsson A, Backman E, Henriksson KG, et al. (1995). Pain analysis in patients with fibromyalgia. Effects of intravenous morphine, lidocaine, and ketamine. Scand. J. Rheumatol. 24: 360-365.

Stegh AH, Chin L, Louis DN and DePinho RA (2008). What drives intense apoptosis resistance and propensity for necrosis in glioblastoma? A role for Bcl2L12 as a multifunctional cell death regulator. Cell Cycle 7: 2833-2839.

Strik H, Deininger M, Streffer J, Grote E, et al. (1999). BCL-2 family protein expression in initial and recurrent glioblastomas: modulation by radiochemotherapy. J. Neurol. Neurosurg. Psychiatr. 67: 763-768.

Warncke T, Stubhaug A and Jorum E (1997). Ketamine, an NMDA receptor antagonist, suppresses spatial and temporal properties of burn-induced secondary hyperalgesia in man: a double-blind, cross-over comparison with morphine and placebo. Pain 72: 99-106.

Wong CS, Lu CC, Cherng CH and Ho ST (1997). Pre-emptive analgesia with ketamine, morphine and epidural lidocaine prior to total knee replacement. Can. J. Anaesth. 44: 31-37. 